\title{
Should all patients with transient ischemic attacks be admitted to a hospital in Brazil?
}

\section{Todo paciente com ataque isquêmico transitório deve ser internado no Brasil?}

\author{
Norberto L. Cabral', Adriana B. Conforto ${ }^{2}$
}

${ }^{1}$ Professor of Neurology, Joinville Stroke Registry, Department of Medicine of the Universidade da Região de Joinville; São José Municipal Hospital, Joinville SC, Brazil;

${ }^{2}$ Professor of Neurology, Stroke Group, Neurology Clinical Division, Hospital das Clínicas, Universidade de São Paulo (USP) and Center for Interdisciplinary Research on Applied Neurosciences (NAPNA), USP; Researcher, Instituto Israelita de Ensino e Pesquisa, Hospital Israelita Albert Einstein, São Paulo SP, Brazil; Visiting Professor, Cleveland Clinic, Ohio, USA.

Correspondence: Adriana B. Conforto; Divisão de Clínica Neurológica, HC/FMUSP; Avenida Dr. Enéas C. Aguiar 255 / 5084; $05409-010$ São Paulo SP - Brasil; E-mail:adriana.conforto@gmail.com

Conflict of interest: There is no conflict of interest to declare.

Received 1 April 2013; Received in final form 17 April 2013; Accepted 24 April 2013.

The 2012 Brazilian guidelines for ischemic stroke recommended periodic educational programs to increase stroke awareness among medical professionals, other health professionals, and emergency services ${ }^{1}$. Also, a Brazilian National Stroke Policy Act published in 2012 established the battle against stroke as a national priority. Education about stroke is a crucial element of this policy.

Recognition of symptoms and signs of transient ischemic attacks (TIAs) can also impact stroke prevention. It has been estimated that up to $20 \%$ of ischemic strokes are preceded by TIAs. Urgent assessment and treatment of patients in "TIA clinics" were associated with an $80 \%$ reduction in the risk of early recurrent stroke, after minor stroke or TIA in the EXPRESS study². Identification of those at highest risk of stroke in the first days and weeks after a TIA would allow rational use of costly secondary prevention strategies, including hospital admission.

Molina and Selim proposed that the ABCD2 score (often used to predict the short-term stroke risk after TIA) represents field glasses that help shepherds visualize a flock at a long distance, in an attempt to discriminate sheep (low-risk TIAs) from wolves (high-risk TIAs) ${ }^{3}$. They suggested that emergent neurovascular evaluation should be performed as soon as possible after TIA presentation regardless of $\mathrm{ABCD} 2$ score.
In clinical practice, how would recommendations of stratification of stroke risk impact TIA management in Brazil?

Limited information is available, but it is known that first, the age-adjusted incidence of first-ever definite and probable TIA, in the Joinville Stroke Register, was two to three times lower (28/100,000 population) than in well-designed, population-based-TIA studies $(59-110 / 100,000)^{4}$. This may reflect low rates of diagnosis rather than low incidence. Second, stroke awareness is poor in the general population; $22 \%$ of subjects interviewed in four Brazilian cities did not recognize any warning signs of stroke ${ }^{5}$.

Thus, in Brazil, it is likely that TIAs are under-recognized and that in the absence of "TIA clinics," patients are discharged without investigation with (at most) a prescription of aspirin. Therefore, borrowing the metaphor from Molina and Selim, field glasses may not help in discriminating wolves from sheep when worn by the blind, or they may simply not be worn as often as they should.

Being pragmatic, until "TIA clinics" become widely available in Brazil and major improvements are achieved in education of health professionals and patients, we suggest that all patients with TIA should be admitted for emergent investigation and treatment.

\section{References}

1. Oliveira-Filho J, Martins SC, Pontes-Neto OM, et al. Guidelines for acute ischemic stroke treatment - Part I. Arq Neuro-psiquiatr 2012; 70:621-629.

2. Rothwell PM, Giles MF, Chandratheva A, et al. Effect of urgent treatment of transient ischaemic attack and minor stroke on early recurrent stroke (EXPRESS study): a prospective population-based sequential comparison. Lancet 2007;370:1432-1442.
3. Molina CA, Selim MM. Hospital admission after transient ischemic attack: unmasking wolves in sheep's clothing. Stroke 2012;43:1450-1451.

4. Fonseca PG, Weiss PA, Harger R, et al. Transient ischemic attack incidence in Joinville, Brazil, 2010: a population-based study. Stroke 2012;43:1159-1162.

5. Pontes-Neto OM, Silva GS, Feitosa MR, et al. Stroke awareness in Brazil: alarming results in a community-based study. Stroke 2008;39:292-296. 